\title{
A philosophical case for big physics
}

\author{
Articulating the case for investment in large-scale physics projects is rarely straightforward. If scientists are to \\ continue to do so effectively in the future, they must learn to grapple with a host of issues that they have perhaps \\ been lucky to be shielded from in the past.
}

R esearch scientists might rationalize the tension between the intellectual motivation for fundamental research and the arguments (let alone the paperwork) used to justify its funding as the price of doing business, but for many it still brings up a deeper sense of discomfort: the frustration of having to explain something that one considers self-evident (broadly speaking, that investing in fundamental research is good for society) to a listener that is either sceptical or, worse, just doesn't see it.

In its most naïve form, this comes across as a sense of entitlement. And unsurprisingly, when that happens it is thoroughly unproductive: a public that is disengaged from its scientific enterprise is unlikely to back it when it matters especially when it requires investment to the tune of billions, as is the case for the largest and most ambitious physics projects.

It is therefore instructive to take a step back and examine the issue from a different perspective. Why should society invest in big science? What benefits does it provide, and to whom? And what are the mechanisms to ensure that these benefits are distributed fairly?

These are big questions, and they can be easily trivialized or, as is often the case among practicing scientists, taken for granted. But if put on the spot, what would our answers be? A recent workshop entitled 'Perspectives on big science and the question of justice' (https://go.nature. com/34mpWxt), hosted by the Royal Society of Edinburgh in the United Kingdom, brought together a multidisciplinary group including philosophers of science, political philosophers, physicists and economists to explore these issues.

The range of different perspectives provided by the speakers underline the breadth of the topic. The first part of the workshop focused on the politics and economics of large-scale physics experiments, and in many ways covered the most familiar ground, at least for physicists: Rolf Heuer and Emmanuel Tsesmelis gave an overview of the main benefits of investing in big science, gleaned from their

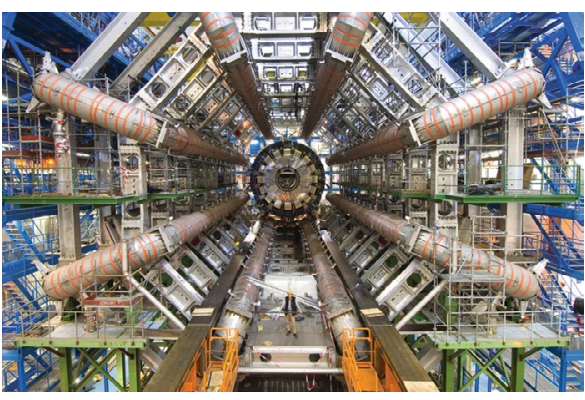

Credit: CERN/Science Photo Library

experience as former Director General and current Head of Relations with Associate Members and Non-Member States of CERN. The wider socioeconomic impact of large scientific projects was then discussed in quantitative detail by Massimo Florio, an economist at the University of Milan. And the practical realities of leading a large-scale facility in its construction phase and keeping science on the political agenda were lucidly described by John Womersley, until recently Director General of the European Spallation Source in Lund, Sweden, and Anne Glover, former Chief Scientific Adviser to the president of the European Commission.

In the case of a science megaproject such as the European Spallation Source, Womersley identified a number of key challenges that, in addition to a compelling science case and adequate technical specifications, must be met for it to be realized: these include strong project management and a credible funding and governance plan, but crucially, also adequate stakeholder engagement and a strong business case that can be articulated in terms of market values such as the jobs, skills and technological innovation.

The issue of stakeholder engagement is especially important. On a local, national and international level, members of the public, students, educators, civil servants and politicians must all see the value of the project and be invested in its success. And as Anne Glover recounted from her time at the European Commission, this involves much more than simply explaining the science or indeed the economics: it involves persuasion, diplomacy and an understanding of all these constituencies' different concerns and incentives, so that they can be involved in the funding decisions.

These conversations set the scene for the second part of the workshop, which focused on the interplay between scientific and social progress and, in particular, the relationship between science and justice. And here it was that the philosophers held sway, by encouraging some deep reflection on who really benefits from these projects.

Michela Massimi, a philosopher of science at the University of Edinburgh and one of the workshop's conveners, raised the uncomfortable question of how exactly scientific progress translates into benefits for society, and pointed out instances where it may not. Ultimately, the public needs reassurance that these benefits translate across the whole of society. There is much current interest in social and distributive justice, but the question is much wider and also includes intergenerational and global justice.

Quite simply, it is legitimate to ask how an investment made today in, say, a spallation source in the south of Sweden will ultimately benefit future generations based in other participating countries. Indeed, as the philosopher Heather Douglas later pointed out for the case of the telescopes built at the summit of the Mauna Kea volcano in Hawaii, there are instances in which the very concept of stakeholder is inadequate, for example, in the case of indigenous groups, who should be considered rights holders instead.

Science has enormous transformative and redistributive power. As society recovers from the first truly global pandemic, there is a golden opportunity to showcase the benefits of science in the coming years. By taking on a range of different perspectives as to what these should be, scientists can strengthen the case for their mission in the context of large physics projects as well.

Published online: 9 June 2021

https://doi.org/10.1038/s41567-021-01278-0 